\title{
Ensino Superior e Educação Básica: Pensamento labaniano, contextos e danças
}

\author{
Jair Mario Gabardo Junior \\ Universidade Federal do Paraná - UFPR, Curitiba/PR, Brasil \\ E-mail: jr_gabardo2@hotmail.com \\ Thaís Castilho \\ Universidade Federal do Paraná - UFPR, Curitiba/PR, Brasil \\ E-mail: tahcastilho@hotmail.com
}

\section{Resumo}

Objetivamos neste texto descrever e refletir sobre duas pesquisas desenvolvidas em contextos educacionais distintos - porém, não desconectadas cujas práticas se basearam na Eucinética de Rudolf Laban. Da primeira, uma proposta de doutoramento em Educação no PPGE-UFPR, realizada em um curso de Bacharelado em Artes Cênicas no interior do estado do Paraná. Da segunda, um estudo exploratório de Mestrado, dentro do mesmo programa, desenvolvida na disciplina de Arte da educação básica localizada na cidade de Curitiba/PR. A escrita emerge das experiências de seus autores em espaços públicos de Educação a fim de propor um cenário polissêmico de análises. Os resultados apontaram para [cor]possibilidades capazes de (re)pensar e (re)criar as propostas de Laban, que não param de produzir sentidos na contemporaneidade. Por meio ao presente estudo, averiguamos uma espécie de condição metodológica frente à Coreologia, tornando-a uma perspectiva didático-filosófica a qual propomos denominá-la por Pensamento Labaniano.
In this article, we aim to describe and reflect about two researches developed in different educational contexts - but not disconnected - in which the practices were based on Rudolf Laban's Eucinetics. The first, it is a PhD research in Education at PPGE-UFPR, carried out in a bachelor's degree in Performing Arts in the interior of the state of Paraná. The second, it is an exploratory study of a master's degree, within the same program, developed in art classes at a middle school in Curitiba/PR. This text emerges from the experiences of its authors in public spaces of Education in order to propose a polysemic scenario of analysis. The results pointed to [body] possibilities capable of think and (re)create Laban's proposals, which do not stop producing meanings in contemporary times. Through this study, we found a kind of methodological condition in front of Coreology, making it a didactic-philosophical perspective which we propose to call Labanian Thought. 


\section{Pulsões de contexto(s) e(m) dança(s)}

Por meio de uma abordagem qualitativa, temos por interesse refletir sobre duas pesquisas promovidas em contextos educacionais distintos - porém não desconectadas - cujas práticas corporais foram baseadas na Arte do Movimento de Rudolf Laban e serão analisadas a partir das experiências de seus respectivos autores.

Da primeira, uma proposta na esfera do Ensino Superior que é fruto de um doutoramento em Educação pelo PPGE-UFPR, desenvolvida pela autora em 2019, na qual os acadêmicos de um curso de Bacharelado em Artes Cênicas, de uma universidade pública do estado do Paraná, foram convidados a explorar a técnica do Ballet Clássico através dos pressupostos labanianos.

Da segunda, uma pesquisa de Mestrado dentro do mesmo programa, realizada pelo autor entre os anos de 2018 e 2019, cujo estudo exploratório foi proposto em aulas da disciplina de Arte nos anos finais do Ensino Fundamental II, totalizando o envolvimento de cinco turmas de $9^{\circ}$ ano em uma escola pública do munícipio de Curitiba/PR.

Entendemos o legado de Laban como um circuito histórico/teórico/prático trilhado por diferentes sujeitos, uma esteira de pensamentos percorrida por múltiplos corpos que se movem em espiral, por isso, sempre atualizada e atualizante. Como sugere Katz (2006), apostamos no pensar-fazer labaniano como uma espécie de meme contaminador e contaminado, como vírus da mente e encarnado corporalmente desde o século passado.

Acreditamos que, na era contemporânea, cada pesquisador pode - senão deve - sugerir novas formas de compreender as teorias do filósofo, dando vida a "um Laban diferente, adaptado a cada contexto em que o seu pensamento, ainda hoje, pare-

10 trabalho intitulado Ensino superior e educação básica: pensamento labaniano, contextos e danças foi realizado com o apoio da Coordenação de Aperfeiçoamento de Pessoal de Nível Superior (CAPES) - Bolsa do Programa Nacional de Doutorado e Mestrado. ce capaz de inventar", desdobrando-se em "novos campos de conhecimento", novas maneiras de pensar-ensinar-criar dança (GREINER, 2006, p. 82).

Ademais, as pesquisas de Mestrado e Doutorado supracitadas estão atreladas aos estudos da Eucinética, e este artigo versa sobre as escoIhas metodológicas dos autores, atravessadas pelos fenômenos socioculturais e políticos que vibram em cada contexto. Objetivamos, pois, analisar os procedimentos metodológicos das aulas de dança os quais sofrem - ao mesmo tempo que provocam - implicações na forma de produção artística ao dispor como base a Arte do Movimento.

Para tanto, organizamos o texto ao iniciar pela contextualização das bases labanianas que fundamentam nossas pesquisas. Posteriormente, seguimos com as seções que apresentam nossas práticas pessoais, cujo foco está nos modos particulares de como nos servimos da abordagem labaniana. Por fim, destacaremos os pontos que nelas se (inter)conectam.

Ao nos debruçar sobre nossos trabalhos, estimamos percorrer a espiral de pensamentos labanianos, e permear por espaços de infinitas ideias que um sistema aberto permite criar. Aderimos por via desse artigo conexões às múltiplas vivências oriundas do legado do Mestre do Movimento 2 no anseio, tão somente, de ampliar seus sentidos. Em outras palavras, concernidos por um entendimento artístico e educacional crítico, alçamos no legado de Laban provocação e busca por infinitas [cor]possibilidades $^{3}$ de atuar artisticamente na área da educação.

Os pesquisadores integram o Grupo ELiTe (UFPR/CNPq) - Laboratório de estudos em Educação Performativa, Linguagem e Teatra-

2 Apelido fornecido à Laban, registrado em obras como a coletânea: MOMMENSOHN, M.; PETRELLA, P. (Orgs). Reflexões sobre Laban, o mestre do movimento. São Paulo: Summus, 2006.

3 A grafia "[cor]possibilidades" sugere o corpo e seu potencial no entre-lugar nas práticas artísticas. Uma condição inventiva instigada pela mediação do professor e pelas relações que cada aluno assume em sala de aula (KOEHLER; GONÇALVES; GONÇALVES, 2018). 
lidades, cujos encontros e discussões coletivas impulsionaram essa escrita compartilhada. agente de sua própria história, recontada/ redançada através da pesquisa coreográfica. (FERNANDES, 2009, p.139, grifo nosso).

\section{Espiral Labaniana:} coreologia em (re)significação

Identificamos que um dos diferenciais das visões de Laban foi o reconhecimento do corpo como o grande articulador e pensador do movimento. Suas teorias foram baseadas numa visão holística, na qual físico, mente e espírito são indissociáveis e formam uma unidade. Por isso, não se pode atribuir apenas à mente a função intelectual e criativa, "não é possível separar conceitos abstratos, ideias e /ou pensamentos da experiência corporal". O corpo (também) corresponde à dimensão pela qual "podemos dizer, pensar, saber e comunicar" (RENGEL, 2006, p. 122).

Para o filósofo, "é a partir do corpo, e de seus movimentos, que somos capazes de nos relacionarmos com o mundo que nos cerca, e dessa forma obter o seu entendimento" (MOTA, 2012, p. 64). As percepções, memórias, organização de ideias não são processos separados e habitados somente no cérebro, pois acontecem por todas as células, escorrem no/pelo corpo.

Partindo dessa premissa, por meio de livros, espetáculos e aulas em seus centros de formação artística, Laban trouxe ao mundo uma teoria, um estudo de viés acadêmico, o qual nomeou de Coreologia, cujo foco está na leitura das "leis ocultas" que regem o movimento, sua composição estrutural e expressiva, a qual se constitui por três frentes: Labanotation, Corêutica e Eucinética. Sendo que a última diz respeito às propriedades dinâmicas e rítmicas dos gestos, que permitem ao sujeito se comunicar, construir sua dança e dramaturgia (MOTA, 2012). Desse modo,

Laban propôs um sistema aberto de troca desafiadora entre teoria e prática, Arte e ciência, tema e método, experiência e linguagem, técnica e criação, pesquisador e pesquisado. Nesta perspectiva, o (passivo) objeto de estudo torna-se um sujeito ativo: o corpo deixa de ser um objeto de especulação científica ou dominação social para tornar-se
Laban aponta que a qualidade de vida do ser humano está relacionada à sensibilidade e consciência de seu corpo, à sofisticação de seus gestos, isto é, ao "domínio do movimento"4, seja em cenas artísticas, ou em situações cotidianas. Não à toa, suas propostas invadiram as escolas regulares da Inglaterra na metade do século $X X$.

Para a Dança Educativa Moderna ${ }^{5}$ de Laban, é importante que

\begin{abstract}
[sejamos] capazes de experimentar relacionamentos nos quais a consciência do eu e dos outros é realçada. O sentimento de alegria que a Dança nos dá nos ajuda a nos harmonizarmos e a ganharmos um incrível sentimento de pertencer. Se no nosso ensino tivermos ajudado as pessoas a enfrentar o medo e conquistar confiança para se comunicar livre, sensível e imaginativamente; se sentimos que possibilitamos que [os alunos] se tornem, mesmo em pequena escala, conscientes de seu potencial e dos outros, então teremos atingido sucesso. Este sucesso é a justificativa de uma educação através da Dança (ULLMANN in LABAN, 1985, apud MARQUES, 2011, p. 78, grifo nosso).
\end{abstract}

As visões labanianas se propagaram no mundo pelas escolas regulares e espaços artísticos, em especial nas Artes da Cena. Por ser um sistema aberto, passível de interlocução, foi ampliado por grandes discípulos e colaboradores. No século passado, desencadeou-se "um processo em que [Laban] foi até ofuscado pelo sucesso de seus alunos: Joss, Mary Wigman, Leeder, Bartenieff..., cumprindo assim seu objetivo, ou seja, colocar em movimento uma ideia, uma emoção, um sentimento" (MOMMENSON, 2006, p. 17, grifo nosso).

4 O termo se refere ao título do livro publicado pelo autor em 1950. Organizado pela discípula e colaboradora Lisa Ullmann, lançado no Brasil em 1978.

5 Refere-se ao livro publicado em 1948, que aborda sua proposta de educação por meio da dança. 
Warren Lamb, por exemplo, entre 1950-60 lançou as bases para o conceito de Forma, que foi estruturada por Irmgard Bartenieff, ao lado da teoria correspondente ao Corpo, em 1965. Então, a Coreologia se desdobrou em quatro categorias: Corpo; Expressividade (Eucinética); Forma; Espaço (Corêutica) - trazendo ao mundo o Laban Movement Analysis (LMA), conhecido também como Sistema Laban/Bartenieff (SCIALOM, 2017).

Essa divisão é "de natureza metodológica, possibilitando a observação e a descrição organizadas. De fato, as quatro categorias estão sempre presentes em todo movimento, porém com diferentes graus de importância ou destaque" (FERNANDES, 2001, p. 9).

No século $\mathrm{XXI}$, incorporadas aos trabalhos de diversas áreas - como as Ciências Humanas, Sociais e da Saúde -, "as ideias de Laban continuam, cada vez mais, sendo difundidas, apesar de nem sempre serem denominadas como tais" (GUIMARÃES, 2006, p. 49). Ecoam na contemporaneidade mesmo que de modo mascarado, diluída em diversos procedimentos e abordagens.

O desdobramento em quatro categorias, contudo, não é de comum aceitação para os diversos núcleos de pesquisa labanianos, pois alguns especialistas preferem a tripartição original. Todavia, entendemos que cada artista-docente-pesquisador tem a liberdade para trabalhar a Coreologia conforme suas intenções e necessidades, de modo a mantê-la viva e pulsante em diferentes espaços e tempos.

De acordo com os estudos de Scialom (2009, p. 116), muitos especialistas apresentam preocupação com tais desdobramentos, ao mesmo tempo que também compreendem que "é competência dos próprios estudiosos e praticantes garantirem a disseminação do legado de acordo com que o próprio mestre almejou", pois, ele mesmo percorreu o caminho em direção à pluralidade. Inclusive, "os labanianos em geral concebem o Universo Labaniano como uma ferramenta 'multiuso'” (Ibidem, p. 118), carregado de possibilidades infindáveis, sendo necessário observá-lo de acordo com cada contexto.

Entendemos, portanto, que (re)significar a
Coreologia não corresponde a recortá-la como convém, deturpando suas bases em prol de interesses egóicos e ingênuos. A liberdade de escolha deve estar aliada à fidelidade e responsabilidade para com os postulados do Mestre do Movimento, imbuída de pesquisas constantes.

Posto isto, para nossas práticas no Ensino Superior e na Educação Básica, consideramos a integração corpo-mente-espírito e apostamos no protagonismo dos corpos dos alunos. Conforme citado, também nos servimos dos estudos da Eucinética, correspondente à categoria Expressividade, trabalhando os Fatores do Movimento de maneiras particulares e condizentes com nossos objetivos de investigação.

No presente texto, aderimos às grafias cunhadas por Fernandes (2006; 2009). A autora afirma que "Laban utilizou o termo Antrieb ou Effort para nomear a atitude interna com relação aos quatro fatores de movimento (fluxo, peso, tempo, espaço), em gradações entre duas polaridades (contido/livre, forte/leve, acelerado/desacelerado, direto/indireto" (FERNANDES, 2009 p. 137).

Porém, mantendo a busca pela pluralidade, não desconsideramos pesquisas recentes que trazem outros apontamentos, como as de Azevedo (2012).

A respeito do Fator Fluxo, nas palavras de Laban (1978, p. 124), "o fluxo tem principalmente a ver com o grau de liberação produzido no movimento", ou seja, refere-se à extravasar ou conter a energia, o que pode deixar fluir ou interromper o ritmo dos gestos, cujas polaridades são denominadas por Fluxo Livre e Contido.

O Fator Peso diz respeito à força e intensidade aplicadas aos movimentos, que pode ser uma ação de vigor com o Peso Forte, tais como socos e pressões, ou então, de suavidade e flutuação com o Peso Leve.

O Fator Tempo, por sua vez, corresponde às dinâmicas de duração e passagem do movimento, isto é, o Tempo Desacelerado, que gera passos lentos, sustentados e prolongados, em oposição ao Tempo Acelerado, que provoca ações mais rápidas, súbitas e instantâneas.

Enquanto o Fator Espaço - que é diferente da 
categoria Espaço, ligada à Corêutica -, abrange a plasticidade das ações a partir do foco do indivíduo dançante. Ao se mover mediante um Espaço Direto, o corpo age com pontualidade e precisão, com o foco numa direção única, geralmente em linha reta, tendo a "sensação do movimento como uma linha estendida no espaço, ou sentimento de estreiteza". Já o Espaço Indireto, abrange ações com múltiplos focos, linhas imprecisas, com inúmeras direções, que transmitem "uma extensão flexível no espaço, ou sensação de estar em toda a parte" (LABAN, 1978, p. 121).

Os Fatores do Movimento são projeções de sensações que "canalizam potencial energético que pode ser conhecido, investigado e até mesmo treinado a partir de estudo prático e atencioso pela via exterior" (AZEVEDO, 2012, p. 363). Assim, é possível instigar os dançantes, seja na Educação Básica ou Superior, a explorar a expressividade do movimento. Afinal, "corpos que se conhecem têm grandes possibilidades de estabelecer diálogos diferenciados com os outros, com o meio e com o mundo" (MARQUES, 2010, p. 206).

\section{Pulsões no Ensino Superior}

A construção da presente pesquisa, integrada a um estudo de Doutorado em Educação pelo PPGE-UFPR, foi inspirada em permitir que artistas cênicos, estudantes do Ensino Superior, ampliassem suas [cor]possibilidades a partir de uma técnica a qual considero inteligente e capaz de fornecer empoderamento artístico: o Ballet Clássico.

Nesse processo, recorri à Coreologia como perspectiva metodológica para se praticar o Ballet, por acreditar que as propostas de Laban, "quando entendidas como campos de significação da linguagem da dança, podem ter papel primordial na compreensão e na desconstrução das técnicas codificadas" (MARQUES, 2010, p. 90). Pois, permite trabalhá-las, justamente, mediante conscientização e interpretação de seus textos e subtextos, de modo a "des-velar, des-construir, des-cobrir, re-configurar as instancias históricas, sociopolítico-culturais, os afe- tos e sentidos embutidos" (MARQUES, 2010, p. 90). Numa esfera como o Bacharelado em Artes Cênicas, frequentada por atores, dançarinos, circenses e demais agentes culturais, as práticas corporais são bem-vindas "quando se trata de trabalhar o corpo, a consciência, o despertar, vivenciar, experimentar, praticar, afetar e ser afetado, interna e externamente" (CARVALHO, 2017 p. 87). Ademais, estima-se que o graduando traga "no seu corpo, no seu movimento e no seu repertório de informações os rastros da sua trajetória de vida, tornando-se o principal protagonista no binômio ensino-aprendizagem" (SILVA, 2016, p. 34).

A partir disso, atuei como professora-pesquisadora convidada durante três meses numa universidade estadual, entre maio a julho de 2019, na disciplina de Expressão Corporal I, com a turma do $1^{\circ}$ ano. Os 44 alunos tinham entre 18 e 27 anos, sendo que a maioria estava cursando sua primeira faculdade, e uma minoria já era formada em psicologia, letras, direito e engenharia. Vieram das regiões Sul e Sudeste, trazendo vivências corporais diversas: 9 deles dançaram Ballet, 8 faziam aulas de Dança Contemporânea, Jazz e/ou Hip Hop, 2 praticavam Yoga, 1 deles era skatista e os demais já haviam participado de treinamentos corporais em Teatro. Somente 1 graduando fez cursos de Educação Somática, e outro era engenheiro mecânico, sem experiência com práticas corporais.

Partindo desse cenário plural, a pesquisa não se restringiu em dar aulas completas de Ballet aos discentes, almejando a realização dos passos dessa dança com excelência. Afinal, uma aula tradicional não atingiria as expectativas desses artistas heterogêneos. Em outra direção, mediei a exploração de poses e movimentos centrais do Ballet, sem buscar um aprendizado exatamente da técnica, mas, por meio dela. O que implicou na sensibilidade para observar como o Ballet se recorta e (des)constrói dentro dessa esfera educacional.

Diferente de uma sala de dança convencional, nosso ambiente não possuía barras ou espeIhos. Imbuídos do legado labaniano, utilizamo-nos do chão, das paredes, de mapeamentos em duplas, 
improvisos individuais e coletivos, além de partituras abertas e fechadas (conforme imagem da figura 1).

Figura 1 - Trabalho de en dehors através das Conexões Ósseas e Forma Fluida 6 .

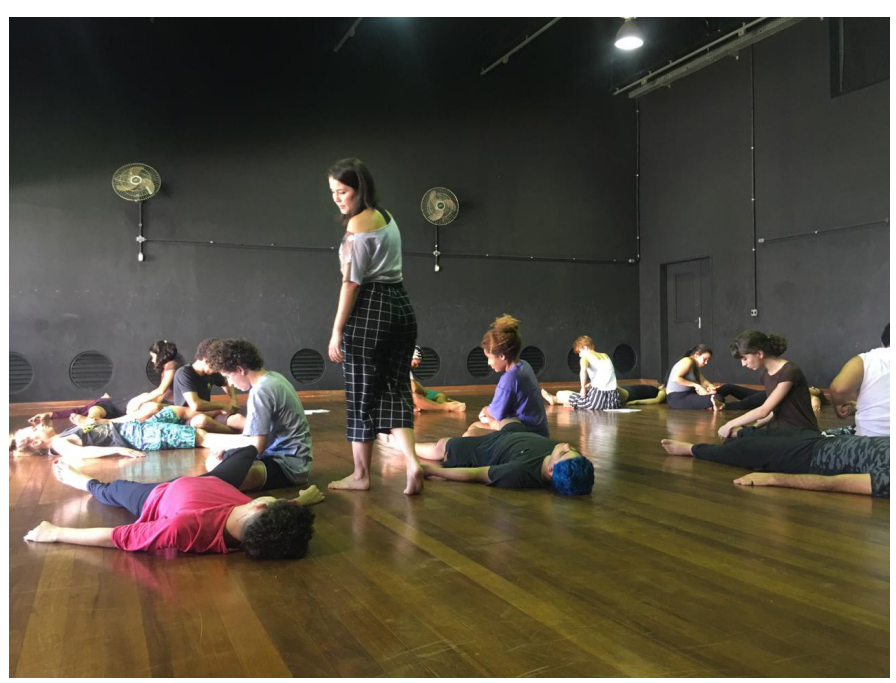

Fonte: Arquivo da pesquisadora, 2019.

De modo geral, durante os encontros nós identificamos e experimentamos as leis ocultas que constituem algumas ações específicas de Ballet. Sentimos o alinhamento corporal do en dehors (rotação das pernas para fora), estudamos as posições básicas de braços e pés, além de passos como: pliés, elevés, retirés, arabesques, souplesses, pas marchés e temps levés.

Percorrendo o Sistema Laban/Bartenieff, pela categoria Corpo, percebemos as cadeias musculares e as Conexões Ósseas que agem durante tais movimentos, enquanto a categoria Forma nos auxiliou a perceber a plasticidade do corpo ao estruturar os gestos e poses. Em seguida, através da categoria Espaço, exploramos os deslocamentos da Cinesfera pelas diferentes Direções, Níveis e Planos. Por fim, a Expressividade serviu para perceber os Fatores do Movimento que já são e/ou que podem ser aplicados nesses passos, conforme a intenção dos artistas.

6 As imagens são fotografias feitas pelos próprios alunos e/ou pela autora, compartilhadas no grupo da plataforma Facebook: Cênicxs - Turma XXI, sendo um espaço virtual de comunicação entre discentes e docentes do curso.
Em relação ao último ponto, o Fator Fluxo foi abordado a partir de uma partitura realizada em pé, composta por: pliés (flexões de joelhos) e elevés (elevação na meia ponta), passando pela $1^{\mathrm{a}}, 2^{\mathrm{a}}$ e $3^{\mathrm{a}}$ posição dos pés. A turma já estava familiarizada com tal sequência, isto é, já haviam memorizado os gestos, as posições dos pés e braços, além de compreenderem alguns elementos oriundos das categorias Corpo, Forma e Espaço dentro dessas ações. Com isso, pudemos jogar com os Fatores do Movimento.

Em silêncio, divididos em pequenos grupos e posicionados em círculos, eles brincaram com as polaridades do Fator Fluxo durante os pliés e elevés (vide figura 2). Como impressões, tanto ao projetarem uma energia liberada, praticamente em frenesi, referente ao Fluxo Livre, como ao aplicarem uma energia interrompida, fragmentada, do Fluxo Contido, logo notaram um estranhamento e a incoerência com as bases dos dois passos.

Os estudantes reconheceram que os movimentos de Ballet possuem qualidades de fluxo específicas, as quais, se forem levadas para extremos, acabam por descaracterizá-los. Além disso, alegaram que se sentiram fazendo meras flexões e elevações de modo mecanizado e desarmônico, e não de fato o plié e o elevé, conforme a técnica clássica sugere. 
Figura 2 - Exploração de Demi Pliés e Elevés.

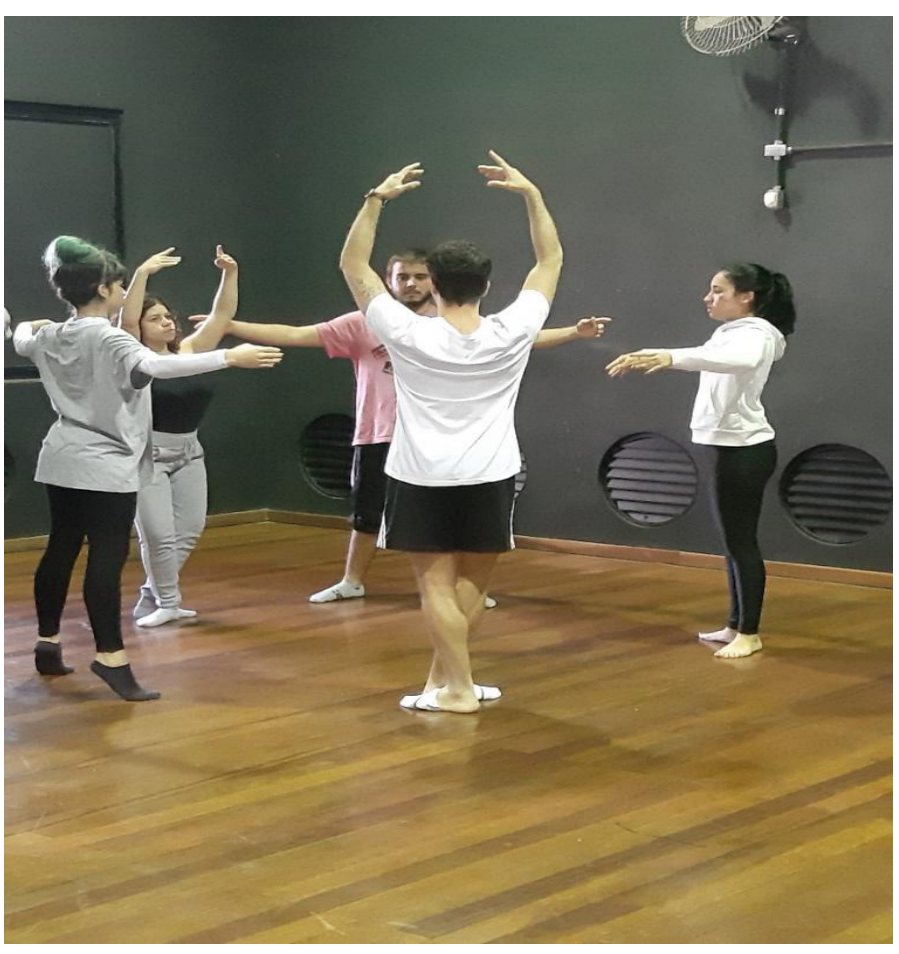

Fonte: Arquivo da pesquisadora, 2019.

Então, passamos a identificar quais são as intensidades de fluxos próprias de cada movimento, a fim de trazer a consciência e o equilíbrio postural. Para auxiliar nesse processo, coloquei o estímulo de uma música clássica, destinada para esse tipo de sequência, que imprime em seus compassos as "deixas" para tais dinâmicas.

Posteriormente, trabalhamos o Fator Peso em partituras abertas com port de brás, nas quais os alunos improvisaram gestos e poses com os braços a partir das polaridades Leve e Forte, até passarem pelas cinco posições de braços, frutos da L'Ecole de L'Opéra de Paris, do Método Francês.

Então, logo identificaram a diferença entre ações suaves e elegantes - estéticas próprias da técnica clássica -, para uma dinâmica fraca, abatida e "sem vida". Notaram que, ao contrário do que reza o senso comum, os bailarinos clássicos não realizam movimentos frágeis e apequenados, pois, a leveza de seus movimentos necessita de certa firmeza e tensão muscular, principalmente na região das es- cápulas (nas costas), que se estende pela parte inferior dos braços. Num paradoxo, a delicadeza dos gestos clássicos carrega dentro de si um trabalho de força e resistência intensos, sendo necessário um equilíbrio exato entre os Pesos Leve e Forte.

Sobre o Fator Tempo, investigamo-lo a partir de deslocamentos pela sala em pas marché - caminhada do Ballet feita en dehors e com os pés esticados. A Desaceleração foi aplicada mediante passos densos e lentos, os quais prolongavam a duração do tempo, e ao acionarem a Aceleração, com ações abruptas e velozes, traziam a sensação de urgência, ao ponto da caminhada se tornar uma corrida pelo espaço.

Em outro encontro, o Fator Espaço foi estudado ao jogarmos com os focos do olhar. No Ballet, todos os gestos possuem uma posição específica de tronco, pés, braços, cabeça e até mesmo do olhar. Em certos passos, os olhos devem ser projetados "por cima" das mãos, acompanhando os dedos como se fossem um prolongamento, mas, em outras ações a cabeça se opõe ao corpo, lançando a visão para pontos contrários do ambiente. Além disso, nas piruetas os olhos necessitam se concentrar num único ponto à frente, para que o bailarino consiga se manter em equilíbrio.

Então, investigamos a ação de projetar o olhar durante passos já conhecidos pelos alunos, como arabesques e por de brás. Depois, realizamos giros como soutenus, estudando a fixação do olhar, numa ação popularmente chamada de "marcar a cabeça".

Ao se familiarizarem com a projeção da visão, brincamos em realizar as mesmas movimentações mediante um Espaço Direto, projetando o corpo para um único ponto da sala, de modo a trazer uma sensação de "linha reta", estreita e afunilada. Em seguida, com o Espaço Indireto, expandindo os focos para múltiplos pontos no ambiente, trazendo a sensação de volume e flexibilidade.

Como retorno, os acadêmicos apontaram que, diferente do que imaginavam, os movimentos do Ballet pouco se utilizam do Espaço Direto, visto que os olhos podem até estar fixos num só ponto, como no caso das piruetas, mas cada parte do corpo se move em diferentes direções. Por vezes, 
se as mãos vão para cima, os pés vão para trás, enquanto os braços estão ondulados, as pernas se esticam, criando uma plasticidade expandida e tridimensional, propriedades do Espaço Indireto.

Para finalizar esse trabalho, os estudantes se reuniram em grupos e sortearam um dos $4 \mathrm{Fa}-$ tores e sua polaridade para construírem pequenas partituras. Ou seja, cada núcleo ficou com uma das 8 ações expressivas e a partir delas criaram células coreográficas com movimentos de Ballet.

Isto posto, a perspectiva coreológica nos auxiliou a praticar a técnica clássica de maneira diferenciada e consciente, de acordo com a esfera educacional e os perfis plurais dos estudantes, cujo foco não era a busca pela realização exímia dos passos, mas explorar o alinhamento postural, as ações e a estética dessa técnica, descobrindo novas [cor]possibilidades.

Ao refletirmos em conjunto, compreendemos que tanto os postulados de Laban agregaram novas proporções, sentidos e funcionalidades para os acadêmicos, tal como o próprio Ballet Clássico. Num processo dialógico, a Coreologia e a técnica clássica estavam imbricadas em processos de (re)significação.

\section{Pulsões na Educação Básica}

Começo essa sessão com três indicações que Laban (1990, p. 18) considerava importantes a respeito do papel da escola para com o movimento: da primeira, cultivar a consciência dos impulsos naturais de expressão dos alunos; da segunda, conservar a espontaneidade do movimento durante e pós a vida escolar; e da terceira, estimular a expressão criativa do movimento por meio ao seu grau de desenvolvimento em práticas individuais e coletivas.

Seu escrito permite pensar de modo atualizado o papel da escola como lugar de experiência do movimento. Tomo, então, uma breve parte dessa sessão para lembrar as atuais leis para a sua efetivação em nosso país. Para tanto, pontuo a alteração e o grifo no ano de 2017 do segundo parágrafo (§ $\left.2^{\circ}\right)$ na Lei de Diretrizes e Bases da Educação Nacional (LDB 9.394/1996) (BRASIL, 1996) cuja mu- dança exclui a obrigatoriedade da arte nos diversos níveis da Educação Básica, e nesse mesmo ano a implementação da Base Nacional Comum Curricular (BNCC) (BRASIL, 2020) que embora promulgue a dança no Ensino Fundamental, a reduz em unidade temática. No Ensino Médio, a arte na BNCC é subjugada às linguagens e suas tecnologias, e a especificidade da dança como amplo conjunto de saberes próprios não é contemplada.

Corroboro com Laban que na escola reside um importante lugar de acesso à dança e na possibilidade dos estudantes em experiênciá-la. É desse múltiplo atravessamento entre dança e escola que trago para o interior desse estudo uma experiência com o Sistema Laban, e consequentemente, contribuir com os discursos que promovam a dança como um direito à Educação.

Esta pulsão se apresenta como minha motivação interna atuando como artista da dança, professor de arte na Secretaria de Estado da Educação do Paraná (SEED/PR) e pesquisador no Mestrado Acadêmico em Educação. Trago para esse estudo um conjunto específico de experiência pelo qual a Eucinética se apresenta como um modo de produção de significados sobre o corpo e $(\mathrm{m})$ movimento.

A prática educativa se externaliza nas aulas da disciplina de Arte em uma escola estadual na cidade de Curitiba/PR durante o ano letivo de 2018, tendo parte da sua análise em 2019. O estudo exploratório foi concebido de modo a integrar a minha prática como docente dessa instituição escolar e dos meus objetivos atrelados ao meu papel de pesquisador a nível de pós-graduação.

A pesquisa me pôs a mover com 153 estudantes entre treze e catorze anos de idade em uma carga horária de 40 horas entre os meses de junho a dezembro de 2018. Nessa conjuntura, incluo 5 turmas do Ensino Fundamental II, letradas pela instituição escolar como $9^{\circ}$ ano A, B, C, D e E. Meu foco, contudo, estava no como o estudo da Eucinética poderia permear as práticas de dança na escola e dos modos de dele se servir em uma ação que tanto toma parte, como se atualiza frente às neces- 
sidades educativas pelas quais convivia na escola.

Compartilhar uma prática educativa pouco se destina a sua forma de reprodução em situações outras. Cada conjunto de experiência assume para si característica peculiar, e por esta razão, enfatizo que o termo "compartilhar" adere "vínculos abertos e fluidos de compreensão, diálogo crítico e participação com o mundo; [a fim de] que possamos compreender, dialogar e participar - dançando - das urdiduras sociais cotidianas" (MARQUES, 2010, p. 174, grifo meu) como sujeitos localizáveis, e por isso, cientes do lugar pelo qual falamos.

A Eucinética se fez por meio de palavras em gesto dando ao corpo do aluno ferramenta para investigar sua própria corporeidade e de se colocar em relação ao seu entorno. Um ato curioso de escuta e voz através do movimento sob consecutivas nuances. Isto me fez refletir a sala de aula como um lugar para sentir os efeitos que o movimento mais consciente poderia ter sobre os estudantes. Significava adesão do movimento para além da busca por "perfeição ou a criação e execução de danças sensacionais" (LABAN, 1990, p.18). Meu olhar residiu em reconhecer as particularidades existentes em cada corpo e pelos modos de como essa corporeidade se orientava via gestos.

Em seu estudo em busca do domínio do movimento, Laban explora amplamente o uso da Eucinética nas ações cotidianas e enfatiza como cada indivíduo tem uma qualidade pessoal de se mover. Para Scialom (2017) a variação dos fatores aumenta a capacidade expressiva do corpo, o que ofereceu ao estudo exploratório condições de olhares diferenciados para as ações diárias e criação em dança.

Vale resgatar de Rengel (2008) a atenção para com práticas escolares que insistem na nivelação do corpo e do movimento, e como o Sistema Laban pode confrontar propostas estatizantes em prol da quebra de binarismos do tipo corpo/mente, sujeito/espaço, arte/vida. Daí a potência da Análise do Movimento por oferecer olhares mais sensíveis aos diferentes corpos que estão na escola.

A incapacidade de apreensão desses estudos sem que sejam postos em prática, exige na escola, ação. O educativo por vias desse sistema que proponho aqui situar, está no como os estudos da Eucinética permearam as práticas de dança a fim de que provocar [cor]possibilidades de orientação pelo movimento e modos de pensar-fazer arte e educação.

Propus aos estudantes em um primeiro momento, após as aulas expositivas, a reconhecerem as polaridades dos fatores do movimento - Peso, Fluxo, Tempo e Espaço - como conexão ininterrupta entre seus corpos e a espacialidade da escola (conforme figura 3). A exemplo, resgatar de suas memórias a brincadeira no corredor (leve/forte), o passo apressado no momento em que toca o sinal (acelerado/desacelerado), o trajeto entre o ir e vir no pátio (direto/indireto), o cumprimento dos encontros e das despedidas (livre/controlado) como partes das aulas. Práticas de movimento em pleno curso da vida.

Num segundo momento, apropriamo-nos da Eucinética como motriz de acolhimento da dinâmica intrínseca no cotidiano e daquilo que extrapola os limites impostos pelos muros da escola. Propus nas aulas condições para pausas, modos de atenção sob diferentes polaridades expressivas por meio de sequências combinadas criadas por mim e pelos estudantes. Para tanto, utilizamos ações do cotidiano escolar e da vida comum repetidos em sequências a fim de tornar mais ou menos latentes as distintas gradações entre as polaridades de cada fator. 
Figura 3 - Eucinética: Partitura coreográfica a partir das polaridades dos Fatores do Movimento. ${ }^{7}$

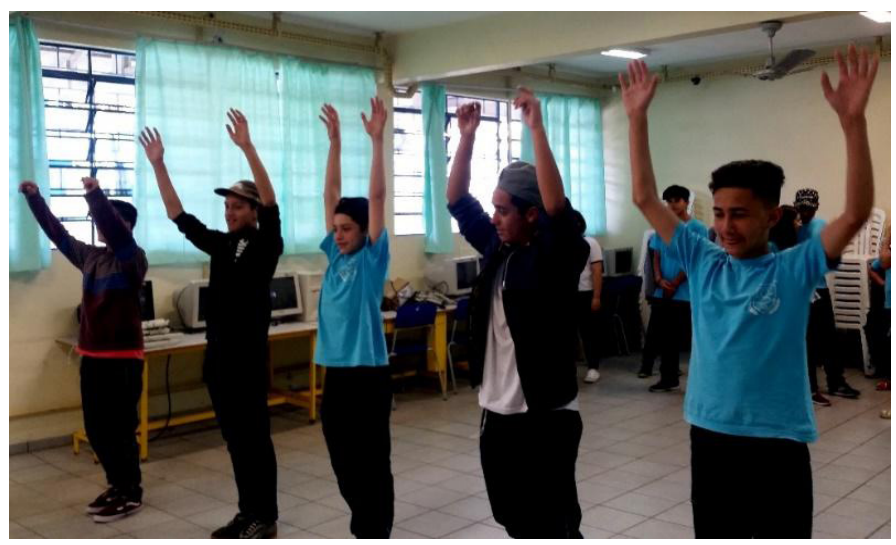

Fonte: Arquivo do pesquisador, 2018.

Incluí nas sequências combinadas momentos para improvisação no intuito de instigá-los a não recair em coreografias decoradas, ao contrário, ansiava por novas proposições inventivas de modo a (des)construir formas corporais no espaço - embasando-me na Corêutica -, e adesão por outros gestos ainda não envolvidos nas suas criações, como por exemplo, criar movimentos em duplas, trios e/ou coletivamente (conforme as figuras 4 e 5 ).

Figura 4 - Eucinética: Improvisação por meio dos estudos dos Fatores do Movimento.

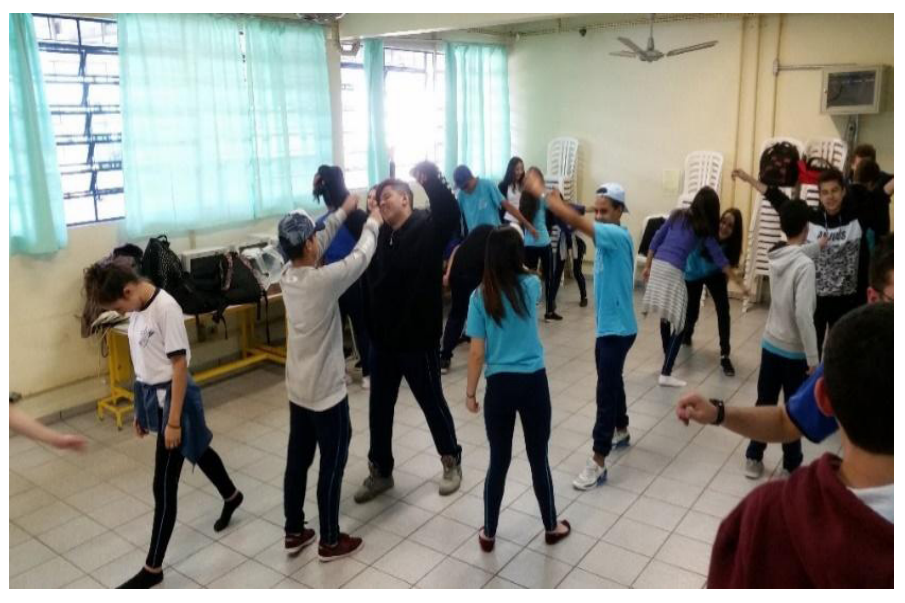

Fonte: Arquivo do pesquisador, 2018.

7 As imagens fazem parte da pesquisa do autor e possuem plena autorização de sua veiculação.
Figura 5 - Eucinética: Composição coreográfica a partir dos Fatores do Movimento.

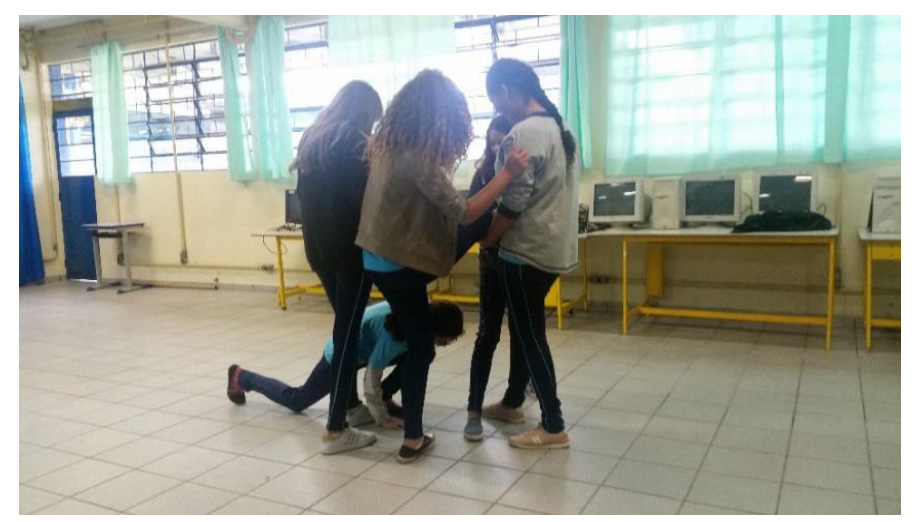

Fonte: Arquivo do pesquisador, 2018.

Ensinar e aprender com o movimento não se trata "de um mero aprendizado de passos. Educar não é tão somente transmitir conhecimento" (RENGEL, 2008, p. 53), tecer um mover corporal crítico faz do pensamento de Laban uma condição atual para a escola de hoje.

A maneira pela qual tomamos - eu e os estudantes - a Eucinética, nos convocou ao movimento reflexivo em nossas rotinas. Por convocar para a sala de aula o movimento corporal rotineiro a fim de compor dança, foi possível dialogar sobre as posturas sociais pelas quais esse mover do corpo nos leva a ter, ou seja, os múltiplos trânsitos que carregamos em nossos gestos e que constantemente interferem em ações na escola e/ou na vida comum. Discutir sobre tais implicações vida/arte, movimento comum/movimento da aula de dança - traz a atenção sobre como nos portamos corporalmente e, principalmente, dos porquês das nossas atitudes corporais internas e externas.

(Trans)formar a peculiaridade cotidiana em dispositivo para criação por meio da Eucinética conferiu propostas que englobam no movimento um dispositivo notável para ideias. Acrescento a corroboração de Marques (2010) ao ter uma Educação em dança na perspectiva de Laban como uma forma ampliada a qual não seja apenas centrada no aluno e na sua experiência pessoal de emoção e expressão, mas atravessada por aquilo que provém da sociedade, 
na relação que esse corpo/movimento estabelece com ela. Experiência muitas vezes tida como insignificante e ignorada em um ensino conteudista.

Penso que a proposta labaniana está constantemente a promover convites para convocar movimentos em situações periféricas da cultura escolar rumo à diálogos cada vez mais multicêntricos e sensíveis.

\section{(In)conclusões: constantes espirais}

A partir de nossos estudos, notamos o quanto o acervo de Laban está vivo e pulsa na contemporaneidade. Encontra-se nas vozes que ecoam pelas universidades brasileiras e nas escolas regulares, sendo revisitado por artistas, pedagogos, educadores físicos, dentre outros profissionais que percebem sua importância para a construção de uma "nova dança", ou melhor, de uma nova maneira de pensar-fazer-ensinar dança. Afinal, não se trata de um método fechado, e sim uma abordagem que enfatiza a leitura do movimento em interação com os espaços internos e externos.

Confirmamos, pois, nossas impressões sobre a Coreologia ser capaz de se (des)construir em cada contexto educacional, ao trazer novas [cor] possibilidades, tanto para os artistas se moverem na docência, como para os alunos, que descobrem as potências expressivas de seus gestos.

As propostas a partir do legado do Mestre, e aqui descritas, revelam-se abordagens didático-filosóficas, a fim de reconhecer a capacidade do corpo em criar e analisar a si mesmo e ao ambiente que o cerca; cujo cotidiano é marcado por fenômenos socioculturais, porém, capaz de ser atravessado por ações artístico-pedagógicas inventivas.

Para além de esquemas ou sugestões metódicas, os Fatores do Movimento foram tratados por nós como uma abordagem sensível, somados a demais noções como a integração corpo-mente-espírito e a capacidade autoral do corpo que fala sobre si, sua trajetória e as vozes que o atravessam.

Potentes, os pressupostos labanianos não só (re)significaram a si mesmos, como tam- bém o cotidiano escolar, refletindo sobre os hábitos e sentidos da Educação Básica, bem como, diferenciaram as práticas dançantes no Ensino Superior e o próprio Ballet Clássico.

Considerando sua pluralidade de abordagem, ponderamos as visões do Mestre como uma perspectiva filosófico-didática que ultrapassa o seu entendimento para além de uma técnica, método, talvez até mais do que um "sistema". Por isso, propomos denominá-las como Pensamento Labaniano. Entendemos que esse termo faz jus às atuações de artistas-docentes que não buscam trabalhar a Coreologia de modo conteudista, fragmentado, como se fosse um programa metódico a ser percorrido, e sim como uma maneira diferenciada de pensar-ensinar-criar dança.

A Eucinética que buscamos explanar se faz uma lente capaz de saber como o movimento pode ser refletido, não às custas do que ele não pode mover, e sim para suas [cor]possibilidades. Portanto, o Pensamento Labaniano é uma forma de ser-estar, de se mover artisticamente na educação. Uma proposição que abrange a Coreologia em sua amplitude, mantendo-a sempre atualizada e atualizante.

\section{Referências}

AZEVEDO, S. M. Delsarte e Laban: raízes e princípios de uma revolução estética. Revista Brasileira de Estudos da Presença. Porto Alegre, v. 2, n.2, 2012. Disponível em: https://seer.ufrgs.br/presenca/article/ view/30294. Acesso em: 5 out. 2019.

BRASIL. Lei No 9.394/1996 - Lei de Diretrizes e Bases da Educação Brasileira. Disponível em: http:// www.planalto.gov.br/ccivil_03/LEIS/L9394.htm. Acesso em: 30 mai. 2020.

Base Nacional Comum Curricular, 2020. Disponível em: http://basenacionalcomum.mec.gov.br/. Acesso em: 30 mai. 2020. 
CARVALHO, A. de. O treinamento de ator na licenciatura em artes (UFPR - Litoral): diálogos Bakhtinianos com professores em formação. 2017. 112 f. Dissertação de Mestrado. Curitiba: Universidade Federal do Paraná, 2017.

FERNANDES, C. Esculturas líquidas: a pré-expressividade e a forma fluida na dança educativa (pós) moderna. Caderno CEDES, Campinas, vol. 21, n. 53, 2001. Disponível em: https://www.scielo.br/pdf/ccedes/v21n53/a02v2153.pdf. Acesso em: 1 ago. 2015.

O Corpo em Movimento: o Sistema Laban/ Bartenieff na formação e pesquisa em Artes Cênicas. São Paulo: Ed. Annablume, 2ed., 2006.

O perfil de movimento de Kestenberg: categorias de análise e aplicação preliminar em dança. Revista Poiésis, v. 10, n. 13, 2009. Disponível em: https://periodicos.uff.br/poiesis/article/view/27013. Acesso em: 9 set. 2019.

KOEHLER, R.; GONÇALVES, M. B.; GONÇALVES, J.C. Teatro e Performance na Educação Infantil: [cor]possibilidades para uma educação sensível. Revista Teias, Rio de Janeiro, v. 19, n. 52, p. 121136, 2018. Disponível em: https://doi.org/10.12957/ teias.2018.29255. Acesso em: 03 abr. 2020.

GREINER, C. O próximo corpo: uma possibilidade de discutir Laban em evolução. In: MOMMENSON, M; PETRELLA, P. Reflexões sobre Laban, o Mestre do Movimento. São Paulo: Summus, 2006.

GUIMARÃES, M. C. A. Rudolf Laban: uma vida dedicada ao movimento. In: MOMMENSON, M; PETRELLA, P. Reflexões sobre Laban, o Mestre do Movimento. São Paulo: Summus, 2006.

KATZ, H. O corpo e o meme Laban: uma trajetória evolutiva. In: MOMMENSON, M; PETRELLA, P. Reflexões sobre Laban, o Mestre do Movimento. São Paulo: Summus, 2006.
LABAN, R. Domínio do Movimento. São Paulo: Summus, 1978.

. Dança Educativa Moderna. São Paulo: Ícone, 1990.

MARQUES, I. Linguagem da Dança: Arte e Ensino. São Paulo: Digitexto, 2010.

- Revisitando a dança educativa moderna de Rudolf Laban. Sala Preta, v. 2, p. 276-281, 2011. Disponível em: http://www.revistas.usp.br/salapreta/ article/view/57104. Acesso em: 2 mai. 2018.

MOMMENSON, M. Apresentação. In: MOMMENSON, M; PETRELLA, P. Reflexões sobre Laban, o Mestre do Movimento. São Paulo: Summus, 2006.

MOTA, J. Rudolf laban, a coreologia e os estudos coreológicos. Repertório, Salvador, n. 18, p. 58-70 2012. Disponível em: https://repositorio.ufba.br/ri/ bitstream/ri/6786/1/44.pdf. Acesso em: 7 jun. 2019.

RENGEL, L. Fundamentos para análise do movimento expressivo. In: MOMMENSOHN, M. e PETRELLA, P. Reflexões sobre Laban, o mestre do movimento. São Paulo: Summus, 2006.

Os temas de movimento de Rudolf Laban (III - III - IV - V - VI - VII - VIII): modos de aplicação e referência. São Paulo: Annablume, 2008.

SCIALOM, M. Laban Plural: um estudo genealógico do legado de Rudolf Laban no Brasil. 2009. 245 f. Dissertação de Mestrado. Salvador: Universidade Federal da Bahia, 2009.

. Laban Plural: arte do movimento, pesquisa e genealogia da práxis de Rudolf Laban no Brasil. São Paulo: Summus, 2017. 
SILVA, E. R. Graduação em Dança no Brasil: professor como orientador e aluno como protagonista. In: INSTITUTO FESTIVAL DE DANÇA DE JOINVILLE; ROCHA, T. (Orgs.) Graduações em dança no Brasil: o que será que será? Joinville: Nova Letra, 2016.

Recebido: 15/06/2020

Aceito: $29 / 07 / 2020$

Aprovado para publicação: 17/11/2020

Este é um artigo de acesso aberto distribuído sob os termos de uma Licença Crea- tive Commons Atribuição 4.0 Internacional. Disponível em: $<$ http://creative commons.org/licenses/by/4.0>.

This is an open-access article distributed under the terms of the Creative Commons Attribution License 4.0 International. Available at: $<$ http://creative commons.org/licenses/by/4.0>.

Ce texte en libre accès est placé sous licence Creative Commons Attribution 4.0 International. Disponible sur: <http://creativecommons.org/licenses/by/4.0>. 